\title{
DICE: Dust impact on climate and environment
}

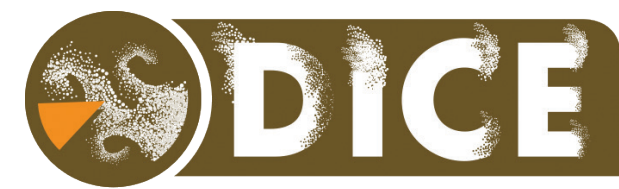

\author{
Gisela Winckler ${ }^{1,2}$ and Natalie Mahowald ${ }^{3}$
}

Natural and human contributions of aerosols and dust are critically important components of climate and Earth system dynamics. Mineral dust aerosols, emitted through wind erosion, affect the radiative budget of the planet, precipitation patterns, biogeochemical cycles, the chemistry of the atmosphere, air pollution and human health. Emission patterns, transport and impact of aerosols on societies are almost certain to change under ongoing climate and environmental change, and it is thus increasingly important to improve our understanding of the impact of dust on climate and environment.

Dust influences the radiative balance of the planet in two different ways: either directly by reflecting and absorbing solar radiation, or indirectly by affecting cloud formation and precipitation patterns (Fig. 1). Mineral dust containing iron can impact marine biological productivity and ecosystem structure by supplying micronutrients to regions of the ocean where iron-scarcity limits primary productivity, and thereby affect the efficiency of the biological pump, a mechanism that could be important in driving ice age cycles.

Dust not only affects climate, but is also influenced by it: its production, atmospheric transport and deposition are sensitive to climatic conditions. Therefore, dust aerosols can act as a tracer of continental conditions and atmospheric circulation.

Since aerosol interactions with climate are a major uncertainty in climate model simulations and predictions (e.g. Myhre et al. 2013), improved understanding of the role of aerosols in past climates represents an important contribution from paleoscience to projections of future climate.

Building on the success of PAGES' Atmospheric Dust: Observations and Modeling (ADOM) working group, the new DICE working group seeks to provide a collaborative platform to build a tight and well coordinated link from paleo-data observations to paleoclimate modeling. This will be achieved by fostering direct interaction between observationalists and theorists, between climatologists and the dust modeling community, and between paleoclimatologists and geochemists.

DICE will convene workshops providing interactions between these communities, drawing input from observationalists and modelers, as well as from scientists focusing on modern times and paleo-perspectives. The goal of this working group will be to develop new databases of dust fluctuations, including deriving more detail from existing data, and to assist in the assessment and development of new prox ies for desert dust in paleo-environments.

Specifically, DICE aims to facilitate the compilation of a next-generation global observational dataset for dust deposition from sedimentary archives for the Late Quaternary, synthesizing spatially and temporally resolved proxy datasets from marine sediments, sediment traps, corals, ice cores, terrestrial deposits and lake sediments. The new compilation will build and extend on the success of DIRTMAP (Dust Indicators and Records of Terrestrial and Marine Paleoenvironments; Kohfeld and Harrison 2001, and Maher and Leedal, this issue) by providing time-series data. The DICE database thus aims to meet the demands created by recent developments in Earth system models, which are now able to run transient simulations and to include more complex interactions between dust and climate. Datasets with high temporal resolution and grain size information will serve as a reference for time-transient studies, e.g. of millennial scale variability or variability associated with abrupt climate change, such as Dansgaard/Oeschger and Heinrich events, or the last glacial transition.

The DICE working group will interact with other paleoscience working groups, such as the International Partnerships in Ice Core Sciences (IPICS), and seek interaction with Earth system science projects rooted in modern observations, such as the International Global Atmospheric Chemistry (IGAC) Project, with the goal of strengthening the links between the paleo community and the modern atmosphere community.

Visit the DICE working group webpage at: www.pages-igbp.org/workinggroups/dice

\section{AFFILIATIONS}

'Lamont-Doherty Earth Observatory, Columbia University, Palisades, USA

2Department of Earth and Environmental Sciences, Columbia University, New York, USA

${ }^{3}$ Department of Earth and Atmospheric Sciences, Cornell University, Ithaca, USA

\section{CONTACT}

Gisela Winckler: winckler@ldeo.columbia.edu

\section{REFERENCES}

Kohfeld KE, Harrison SP (2001) Earth Sci Rev 54: 81-114 Myhre G et al. (2013) In: Stocker TF et al. (Eds) Cambridge University Press, 659-740

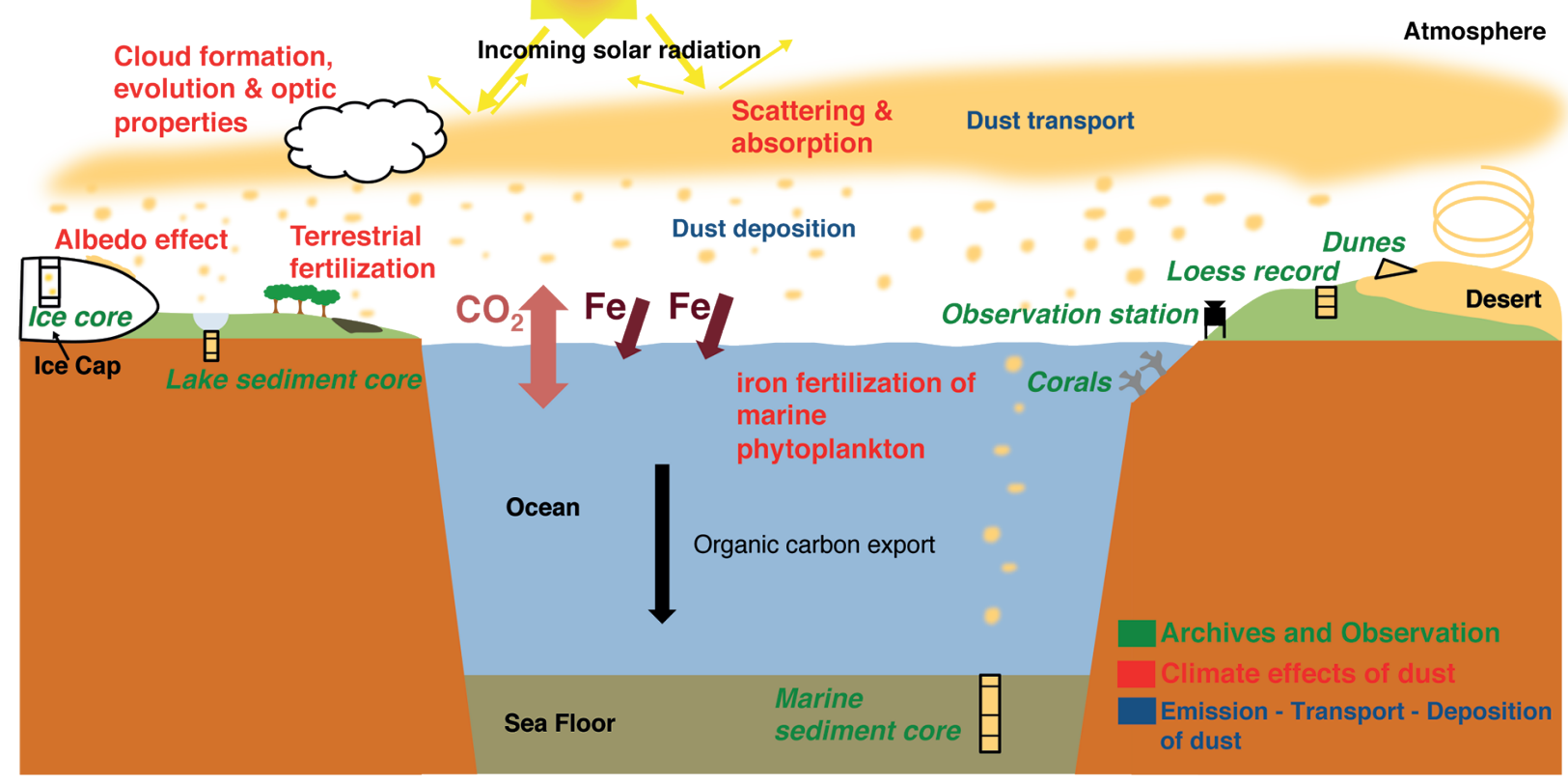

Figure 1: Schematic showing the interactions between mineral aerosols and climate. 